\title{
La Convergencia Interdisciplinaria En El Contexto Educativo De Secundaria En La Aplicación Del Principio De Corresponsabilidad Para Mejorar La Actividad Del Docente Como Intelectual Orgánico
}

The Interdisciplinary Convergence In The Secondary Educational Context In The Application Of The Principle Of Stewardship To Improve The Activity Of The Teacher As An Organic Intellectual

\section{(D) William Aguirre Marín ${ }^{1}$}

Recepción: Abril 12 de 2021 Aprobación: Mayo 27 de 2021

Publicación: Junio 30 de 2021

Cómo citar este artículo: Aguirre M, William (2021). "El Contexto Educativo De Secundaria En La Aplicación Del Principio De Corresponsabilidad Para Mejorar La Actividad Del Docente Como Intelectual

Orgánico". 


\section{Resumen}

El presente artículo expone las ideas centrales del marco de referencia teóricoque sirvieron parala construcción teórica de las ideas educativas fundamentales que orientaron el texto de referencia "El sentido del principio de corresponsabilidad frente a las prácticas pedagógicas de los docentes, el papel de la familia y la política educativa" para aspirar el Doctorado en educación de la Universidad Tecnológica de Pereira.

En este sentido el presente texto señala la convergencia interdisciplinaria y teórica que permite orientar la necesidad del principio de corresponsabilidad y función fundamental que convierte al docente en "intelectual orgánico" en el quehacer del acto educativo en ejercicio de la ejecución del derecho a la calidad de la educación, que lo interpela por contribuir con su liderazgo a agenciar procesos de cambio.

Palabras clave: Intelectual orgánico. Hegemonía. Pedagogía. Principio de Corresponsabilidad. Desarrollo Stewardship. Human development. humano. Hermenéutica crítica. Critical hermeneutics. Liberty.

\section{Abstract}

This article presents the central ideas of the theoretical frame of reference that served for the theoretical construction of the fundamental educational ideas that guided the reference text "The sense of the principle of co-responsibility in the face of the pedagogical practices of teachers, the role of the family and educational policy "to aspire to the Doctorate in education from the Technological University of Pereira.

In this sense, the present text indicates the interdisciplinary and theoretical convergence that allows sustaining the need for the principle of co-responsibility and fundamental function that turns the teacher into an "organic intellectual" in the task of the educational act in exercise of the execution of the right to quality of education. education, which challenges him to contribute with his leadership to

Keywords: Organic intellectual. Hegemony. Pedagogy. Principle of agency processes of change. Libertad. 
La Convergencia Interdisciplinaria En El Contexto Educativo De Secundaria En La Aplicación Del Principio De Corresponsabilidad Para Mejorar La Actividad Del Docente Como Intelectual Orgánico

\section{Desarrollo}

El presente artículo se propone orientar reflexiones pertinentes y conducentes a la actividad docente en relación con las exigencias que el impone el siglo XXI desde el punto de vista social, la necesidad de entender la dimensión económica de las relaciones sociales y su repercusión, así como las cuestiones políticas que derivan de su actividad como intelectual orgánico en el sentido en lo guía Gramsci como autor referente de las teorías de los procesos escolares para la implantación de principios educativos que permitan una educación ética de la autonomía del pensar, en el marco de una dimensión normativa y axiológica en el que se desplazan los fines propios de la educación.

Las teorías educativas que se vinculas con las teorías políticas generan una reflexión directa sobre el papel del docente, pues es el responsable de los agenciamientos fundamentales de las actividades del sistema escolar, siendo en este sentido desde donde se genera la pertinencia de figurar un intelectual orgánico en el docente como garantía de compromiso y eficacia de los procesos educativos, siendo así el que acto educativo tiene una dimensión político-social que permite vincular especialmente el principio constitucional de la corresponsabilidad, quepermitelaconvergenciainstitucional interdisciplinaria para la definición y organización de los procesos educativos que implique una unidad en la planificación, en el establecimiento de objetivos curriculares que manifiesten los objetivos político educativos.
Para esto es fundamental que el docente no se vea inmerso en las paradojas de la cotidianidad docente, en un procrastinar constante en la reproducción autómata de contenidos y procesos institucionales sin reflexión, sin incluir sus esfuerzos investigativos, sin utilizar sus expectativas e ideas creativas de cambiar lo que debe ser cambiado desde el aula, esta es una idea de resistencia para el docente ante las pautas implantadas por la institucionalidad, que tienden a desvirtuar el discurso de la calidad suprimiéndole la reflexión pedagógica imprescindible para defender siempre las variadas dimensiones del ser humano que se realizan en el acto educativo, en la práctica pedagógica del docente que supera sus paradojas, cree en lo que investiga y defiende las realidades de su contexto para superarlas, para evitar la indolencias de las prácticas institucionales que priorizan la eficacia de los procesos de tipo administrativo en perjuicio de las metas pedagógicas y la calidad de la educación.

En este sentido las reflexiones derivadas de las propuestas Gramscianas se relacionan con los desafíos éticos de la educación en el siglo XXI en el entendido de que el derecho a la calidad de la educación plantea propósitos de desarrollo humano que requieren planteamientos político-jurídicos en el marco de la administración pública del derecho a la calidad de la educación como corresponde en el Estado educador constitucional, social, democrático y ambiental de derecho, con el propósito fundamental, además, de oponerse, como lo expresa Calandín, J.G. (2018) "al concepto instrumentalista de la 
educación que la deja a merced de los intereses del mercado y aboga por una reflexión que trasciende el ámbito de la descripción sociológica y nos sitúa en el de la ética” (p.75).

Esto nos permitirá que el docente y la docente tenga presente en el acervo de sus creencias, convicciones y pautas, la diferencia entre la instrucción y la enseñanza, en el entendido de las implicaciones éticas en la personalidad de los individuos que se educan y también en la mentalidad o acervo de ideas educativas del docente en relación con el horizonte de objetivos humanistas de la educación; pues, precisamente la instrucción se refiere a un conocimiento técnico y esto neutraliza el aspecto axiológico e intereses epistemológicos de especial relevancia para los docentes.

Pero es una neutralización que implica posteriormente la configuración de un discurso educativo expresado en una racionalidad científico técnica que se manifiesta en la utilización de terminología derivada de ideologías económicas que en el diario acontecer del acto educativo de aula se utilizan para viabilizar los procesos educativos en el marco de la administración del derecho a la calidad de la educación que termina por convertirse en la calidad de los procesos técnicos de los procesos administrativo-educativos $\mathrm{y}$ los indicadores que deben resultar. Esto excluye precisamente la construcción de una racionalidad desde los valores, desde la terminología moral evitando que tanto el estudiante como el docente sea considerado como el objeto de un proceso.

\section{Marco de referencia}

Ante esta situación el conjunto de los docentes que tienen conciencia del estado de vulnerabilidad de los estudiantes y las estudiantes y esto interpela la función docente en el entendido del deber forma una conciencia y una homogeneidad que contribuya a la unión de propósitos comunes, creando así sus propios intelectuales en este contexto pues la figura del intelectual precisamente a relacionar las características del ser y el saber hacer para que sea funcional al contexto, al grupo del que se surge y trabaja para transformar una realidad, así lo señala Gramsci (1967).

por intelectuales es preciso entender no sólo aquellas capas comúnmente designadas con esta denominación, sino en general toda la masa social que ejerce funciones organizativas en sentido lato, tanto en el campo de la producción como en el de la cultura y en el políticoadministrativo (p. 412).

La función pues del docente nos remite a un operador fundamental de una de las dimensiones por medio de las cuales el Estado cumple sus fines (el trabajo y la educación), en este caso específicamente la educación como garantía del desarrollo de la personalidad humana y la cultura social en general, por esta función en la estructura social el docente es un intelectual orgánico, oponiéndose al intelectual tradicional, definición que es metodológica pero además adquiere un sentido especial, porque interpela al 
docente a convertirse en protagonista no sólo de los procesos educativos sino de los sociales en general.

Entonces todos somos intelectuales, porque utilizamos los dispositivos cerebrales para gestionar los deberes de la vida que le corresponde a toda persona consciente de su realidad, pero Gramsci distingue el intelectual orgánico por su función fundamental social, así lo expresa Gramsci (1967)

Todo grupo social que surge sobre la base original de una función esencial en el mundo de la producción económica, establece junto a él, orgánicamente, una o más capas intelectuales, que le dan homogeneidad y conciencia de su propia función, no sólo en el campo económico, sino también en el social y en el político (p. 21)

Precisamente, en este propósito dedefenderala sociedaddelahegemonía del mercado y de la exclusividad del discurso técnico es pertinente considerar la implementación de la hermenéutica crítica con el fin de describir los fines educativos, cristalizarlos y además generar planes, programas $\mathrm{y}$ proyectos más concretos y cercano a las realidades sociales y culturales de las comunidades educativas, pues precisamente, humanizar la actividad docente y educativa en general esto como lo expresa J.G. Calandín (2018) "no radica en describir y explicar sino en tratar de entender el sentido de los acontecimientos humanos, en tratar de desentrañar la intención del comportamiento humano” Pág. 79.
En este sentido la idea planteada tiene un carácter de conveniencia social poner a la educación en la perspectiva del cultivo de la humanidad, pues precisamente la formación de lo humano es lo que permite reforzar el protagonismo de las humanidades, es decir, las capacidades reflexivas $y$ críticas que generen un legado en cuestiones centrales del ser humano lo que es pertinente además a la construcción de una democracia a partir de la formación ético-cívica de la ciudadanía.

La formación para la autonomía del pensar sólo puede ser posible por el formador orgánico, porque es un miembro activo de la sociedad, y al educar en la autonomía educa para la libertad del sujeto y en este mismo horizonte para la libertad de la sociedad, cultivando lo humano, aquí resulta relevante el concepto de libertad y en sentido se debe manifestar que la libertad; la libertad ha sido abordada desde perspectivas diversas de acuerdo a las áreas de conocimiento en las que este concepto se encuentre involucrado, entonces en la economía se habla de libertad, en política se habla de libertad, en filosofía y en la dimensión social de la sociedad en general, también se habla de libertad, diferenciándose por los enfoques que se le dan de acuerdo a la función que requieran.

En este orden de ideas la libertad planteada desde I. Berlin es una libertad personal con implicaciones sociales en el entendido de las decisiones que tomamos en nuestra vida cotidiana nos determinan, pues la autonomía individual está expuesta a las contingencias y presiones de 
la comunidad política en la que se está inmerso, aquí también debe considerarse la comunidad familiar y social, pues esta independencia es lo que le permite lo que determina la felicidad del individuo, para que en el marco de esta ambivalencia individuosociedad, este pueda proyectar sus deseos racionales, a la vez que controle adecuadamente sus deseos irracionales en beneficio de la polis; es el ejercicio del poder que se determina desde el interior.

En este sentido la perspectiva de Kant en el texto Autonomía de la voluntad hace referencia a una postura que puede plantearse que tiene similitudes o más bien, se ajusta a la noción de libertad que se vislumbra en el texto de la Dos ideas de libertad; en el entendido de que la capacidad que adquiere el individuo de proponerse así mismo pautas que lo auto-regulen, generan una dinámica de libertad propia, que debe de ser característica de un Estado educador, estas voluntades libres capaz de imponerse dominio en concordancia con sus propios deseos, es un rasgo de libertad, entonces, el sujeto se pone fines, que le permiten interpelar la otredad desde unas consideraciones arraigadas en su propia dignidad en la forma de relacionarse con los demás; en consecuencia, utilizando perspectivas Kantianas, el sujeto no es un simple medio, sino una voluntad libre, porque se domina así misma, para enfrentarse a la comunidad que aborda como un estamento global que también debe tener fines, en el que a su vez se desarrolle el mismo.

\section{Discusión}

En este orden de ideas, la capacidad de un sujeto de autoregularse le permite apropiarse de sus propios deseos por medio de la razón que legisla sobre sus acciones, así construye una libertad fundamentada en un dignidad que consiste en el seguimiento de parámetros propios en el desarrollo de unos niveles de moral que se convierten en deberes, esto el sujeto lo puede trasladar a la comunidad o Estado, con el fin de proyectar sus deseos de realización por medio de disposiciones coactivas construidas por el conjunto de voluntades libres que representan los sujetos que se dominan así mismo con el propósito de converger en deseos racionalizados y constituyen la soberanía o el poder constituyente primario.

La idea de la libertad que proviene del dominio de los deseos que se supeditan a la razón, una razón ciudadana, es decir una libertad supeditada una teleología de formación de los valores ciudadanos; este planteamiento es muy importante en el marco del Estado según la interpretación que se hace en el presente texto, pues es el dominio de la razón, sobre los deseos irracionales que pueden hacer perder el contrato social, la libertad de los ciudadanos, como en el caso Colombiano, que durante décadas siniestras se optó por la guerra para mantener privilegios irracionales, no obstante teniéndose la posibilidad de una salida negociada del conflicto, que hace que el Estado fallido no sea un planteamiento de simple diatriba, sino una consecuencia del debilitamiento del Estado como consecuencia de la guerra. 
La Convergencia Interdisciplinaria En El Contexto Educativo De Secundaria En La Aplicación Del Principio De Corresponsabilidad Para Mejorar La Actividad Del Docente Como Intelectual Orgánico

Esta postura sugiere la posibilidad de una sociedad que requiere la formación de ciudadanos desde el domino propio que genere un autogobierno como personas, que haga posible la constitución política como proyecto de sociedad, capaz de construirse desde la libertad y para la libertad.

De igual manera debemos decir que la libertad que se vislumbra en la república nos es clara, pero nos permite construir desde el sujeto una idea que redunde en el beneficio de un ideal de bienestar para el Estado, pero en el que el individuo se una clave de dignidad, pues es capaz de ser libre, por la razón que delibera, que realiza acciones meditadas que le auto-regulan con miras una realización superior en función de un ideal de Estado, pero paralelamente, evitando que desde el Estado, lo que hace el ser humano libre y se convierta al hombre en un prototipo que debe crearse aun adversando la polis.

Libertad es poder construirse así mismo, a partir de uno mismo, sin que sea condicionado por ningún estamento del poder, sino como autonomía del pensar "el Estado necesita un orden social" no siendo así el hombre como diría T. Hobbes se convertiría en un lobo para el hombre (teoría pesimista). Pero es necesario salir de ese estado y depositar la libertad en el Estado, sin embargo, ese orden se naturaliza, se cosifica, se transforma en autoritario, porque finalmente es el orden de la casta dominante, que domina desde el Estado y otros grandes instrumentos de dominación, que en el horizonte de sentido de este texto entendemos con Gramsci como hegemonía. En ese sentido, Guy Debord (1995) señala "toda la vida de las sociedades modernas de producción se manifiesta como una inmensa acumulación de espectáculos. Todo lo que antes se vivía directamente, ahora se aleja en una representación”. Pág. 46. De lo que podemos mencionar precisamente que la organización social se presenta con la imagen de un espectáculo pretendiendo paralizar la historia en función de los intereses que defiende el mercado y que el autor francés señala como la falsa conciencia del tiempo, aquí el docente como intelectual orgánico debe constituirse en una garantía de resistencia en contra de los sistemas de manipulación de la sociedad como lo son la televisión, las redes sociales, la publicidad, la iglesia cualquiera sea su orientación religiosa y las características mismas del sistema escolar, siendo el docente garante sólo del cumplimiento de la constitución en tanto protectora del derecho a la calidad de la educación teniendo como teleología el desarrollo de la personalidad humana, es decir, poniendo a la persona como sujeto de derechos en el centro del acto educativo que genere conciencia.

La conciencia del sujeto, es lo más alto que puede tener, es pensar libremente el mundo y su situación en el mundo, posibilidad de autoconocimiento, siendo en el mundo es lo que el poder quiere dominar. El hombre es historia, hace historia y la historia lo hace a él. Cuando llegamos al mundo la historia ya está hecha $y$ es la que nos hace. El desarrollo de la historia ha sido violento. La tarea del poder comunicacional es acostumbrarnos al horror de la historia, 
concuerdan con el poder militar, a que eso sea algo natural. El sujeto manipulado es una tranquilidad para el poder, si el sujeto esta manipulado, es porque esa persona no tiene una sola idea que el poder le haya inoculado en su mentalidad, la ideas son inculcadas a través de todos los medios, monopolios comunicacionales y los oligopolios comunicacionales.

En este punto es conveniente hacer una referencia a lo que Foucault denominó como el sujeto otro, en el sentido de que el sujeto otro es el sujeto que no se pertenece así mismo, el sujeto que no piensa por sí mismo, no habla por sí mismo, que no se dirige al otro por sí mismo. Es un sujeto que está construido en exterioridad, es pensado, es interpretado, todo le viene de afuera podríamos decir que lo único que hacen es pasar por el mundo no siendo ellos, siendo lo que el poder quiere que sean, siendo meros seres obedientes al poder. Un ciudadano participativo de un Estado democrático no debe ser obediente y en caso de ser obediente debe ser obediente eligiendo algo auténticamente desde sí mismo. Elegir algo porque se ha decidido que se está de acuerdo, es diferente, desde ese punto de vista no se es obediente, desde la auténtica libertad, se adhiere a algo, es muy distinto ya no es un sujeto otro.

La formación de lo humano es algo que no corresponde un grupo selecto o exclusivo de intelectuales, sino que consiste en una transmisión cultural en la que la sociedad, en el marco del principio de corresponsabilidad debe implicarse, todos los miembros participar de las reflexiones que le conviene a las situaciones coyunturales, pues además, todo profesional es un ser humano, un ciudadano activo en una sociedad que debe atender las exigencias éticas y humanas que las necesidades sociales requieren, en este sentido Gramsci (1967) expresa que "podría decirse que todos los hombres son intelectuales, pero que no todos tienen en la sociedad la función de intelectuales" Pág. 26.

En este sentido le corresponde al docente, como intelectual orgánico que implicarse activamente en la formación ética con el enfoque humanista poniendo de manifiesto el cultivo de las humanidades ante el protagonismo creciente de las ciencias naturales y sociales de la educación. Esto es lo que viabiliza la concreción de la educación valores humanos, frente a la instrucción, el adiestramiento y el adoctrinamiento. Ante esto la Unesco ha señalado sobre la visión humanista que debe ser " $u n$ enfoque integrado, basado en sólidos fundamentos éticos y morales", no se trata de un humanismo cientificista sino de un humanismo ético:

se puede afirmar que mantener y aumentar la dignidad, la capacidad y el bienestar de la persona humana en relación con los demás y con la naturaleza, debería ser la finalidad fundamental de la educación en el siglo XXI. Los valores humanistas que deben constituir los fundamentos y la finalidad de la educación son: el respeto a la vida y a la dignidad humana, la igualdad de derechos y la 
La Convergencia Interdisciplinaria En El Contexto Educativo De Secundaria En La Aplicación Del Principio De Corresponsabilidad Para Mejorar La Actividad Del Docente Como Intelectual Orgánico

justicia social, la diversidad culturaly social, y el sentido de la solidaridad humana y la responsabilidad compartida de nuestro futuro común. Hace falta un planteamiento dialógico del aprendizaje, como el que proponen, por ejemplo, Martin Buber y Paulo Freire. Hay que rechazar también los sistemas de aprendizaje que alienan al individuo y lo tratan como una mercancía, así como las prácticas sociales que dividen y deshumanizan a la gente. Es esencial educar en estos valores principios si queremos conseguir la sostenibilidad y la paz (UNESCO, 2015:38).

Precisamente, con el fin de sustentar desde lo normativo la perspectiva humanista que la humanidad ha señalado con respecto a los fines de la educación, estos conceptos y elemento fundamentales los vemos expresados inicialmente en la Declaración Universal de los Derechos Humanos así: "la educación tendrá por objeto el pleno desarrollo de la personalidad humana y el fortalecimiento del respeto a los derechos humanos y a las libertades fundamentales; favoreciendo la compresión, la tolerancia y la amistad entre todas las naciones $y$ todos los grupos étnicos o religiosos, $y$ promoverá el desarrollo de las actividades de las naciones unidas para el mantenimiento de la paz". Artículo 26 DUDH.
En el sentido del desarrollo de la personalidad humana, podemos mencionar precisamente el enfoque de Piaget, en el entendido de nos excluir o separar el desarrollo de las facultades intelectuales y las facultades humanas, haciendo posible la integración permanente de los enfoques axiológicos humanos en procura de una educación que no suprima los contextos del estudiante y las actividades autónomas a partir de su realidad concreta, en este sentido lo expresa J.G. Calindín (2018) siguiendo a Piaget podemos afirmar que para ser libre es necesario desarrollar activamente la inteligencia de modo que la propia educación no sea impositiva y que coactiva de ciertos valores $y$ convenciones sociales, sino que lo decisivo es que el educando estimule $y$ desarrolle las capacidades intelectuales de pensar por si mismo. Libertad y ser activo intelectualmente van de la mano. Solo desde métodos educativos activos, que fomenten la autonomía es posible desarrollar la actividad intelectual. Estos métodos a los que apunta Paiget son los de la colaboración y el reconocimiento entre las personas (p.95).

Este sentido moral de los fines de la educación se concreta en el sentido de la moral como preservación y desarrollo de las sociedades humanas, en este sentido podemos expresar 
desde la perspectiva de Durkheim, por ejemplo, Geneyro. J.C. (1991)

la moral es el conjunto de representaciones colectivas que sintetizan ideales, conocimientos $y$ aspiraciones de los hombres, en tanto civiles, que se expresan por medio de leyes, normas, costumbres y estados de opinión (p. 50).

De acuerdo con lo anterior la conceptualización y trabajo de la dimensión moral es fundamental y provechosa para el docente pues tiene elementos que activan positivamente su labor como intelectual orgánico y su relación con la misión de formación de ciudadanía humana, pues la moral es fuente de solidaridad y de conflictos personales, grupales y sociales, acervo que el intelectual orgánico pues trabajar desde la visión social con el propósito de organizar sociedades superiores, en es este sentido Geneyro J. C. (1991) manifiesta que:

es moral todo lo que
constituye fuente de
solidaridad, todo lo que
fuerza al hombre a contar
con otro, el hombre no es
un ser moral sino por vivir
en sociedad, puesto que la
moralidad consiste en ser
solidario a un grupo" (p.
67 ).

En este sentido la moral cívica, laica y democrática es y debe ser fundamental en la argumentación del docente como intelectual orgánico y líder educativo activo haciendo posible la crítica, la discusión e interpelación institucionales de los temas que resultan moralmente abordables para la solución de las problemáticas educativas de las instituciones educativas de secundaria, situaciones que involucren los diferentes estamentos institucionales, y que además esa actividad constituya una fuerza de resistencia al sistema neoliberal que captura los propósitos de desarrollo humano en el marco de lo educativo-moral.

Desde una perspectivajurídica el docente como intelectual orgánico tiene en el contexto del Estado colombiano, la constitución política de 1991 que tiene los elementos pedagógicos que facilita la política educativa que le permite convertirse en un agente capaz de hacer posible la transición del Estado educador liberal al Estado educador constitucional, social, democrático y ambiental de derecho, evidenciando en su acto educativo y en las actividades de su estamento docente, las prácticas políticas y administrativas del derecho individual $y$ social fundamental a la calidad de la educación, para una formación social, participativa y con valores democráticos.

Interpelando a la admiración educativa en los niveles nacional y local con relación a su la política educativa y su administración se ajusta efectivamente al comportamiento que le correspondiente al principio constitucional y legal de la formación integral de sujetos culturales, es decir, capaces de comprender su realidad ambiental, es decir, social, cultural y productiva, para interactuar moralmente con los conocimientos apropiados y gestionar las transformaciones de sus prácticas sociales. 
La Convergencia Interdisciplinaria En El Contexto Educativo De Secundaria En La Aplicación Del Principio De Corresponsabilidad Para Mejorar La Actividad Del Docente Como Intelectual Orgánico

Lo anterior es pertinente como contenido que despliega a diario el docente en su quehacer institucional recreando las condiciones subjetivas y objetivas pertinentes a la formación de ciudadanos con autonomía del pensar, gestores de un paradigma plural, en el escenario de una racionalidad comunicativa moral, pues el derecho a la educación no es a cualquier clase de educación, sino a una de calidad que posibilite la formación de la autonomía del pensar. En el caso del derecho social fundamental a la educación, es claro que la fundamentalidad del derecho es para desarrollar la personalidad humana, como lo hemos venido abordando, es un derecho de implicaciones morales y no sólo legales.

El sentido de lo normativo en lo educativo es fundamental y vale la pena señalarlo en el sentido de que el carácter irreductible de lo moral se sustenta en un sentido normativo, no implica simplemente lo que es, sino lo que debe ser. Cómo Kant subrayó, el deber no se identifica con lo que es. Por esto, si el bien implica un deber, no puede ser detectado mediante una simple observación de lo que es. El bien intrínseco no tiene ningún significado fuera del de "deber ser", al igual que lo justo no tiene otro significado fuera del de "deber hacer" el carácter indescriptible propio de los conceptos éticos de "bueno" y "justo" es exclusivamente una consecuencia del hecho de que en ellos está implicado el concepto "deber"; lo anterior implica pues la relación de la moral con la solidaridad como exigencia de lo que debe ser el ideal social que vincula a la educación como dimensión formadora de ciudadanía y articuladora de los procesos sociales y culturales.

\section{Conclusiones}

El docente como intelectual orgánico haciendo parte fundamental de un fin fundamental Estado Social de Derecho que es la educación debe convertirse en líder del acto educativo en el marco de la comunidad educativa exigiendo la participación de todos los estamentos por medio del principio de corresponsabilidad. En este sentido le correspondeal docente, comointelectual orgánico que implicarse activamente en la formación ética con el enfoque humanista poniendo de manifiesto el cultivo de las humanidades ante el protagonismo creciente de las ciencias naturales y sociales de la educación.

En este sentido le corresponde al docente, como intelectual orgánico que implicarse activamente en la formación de ciudadanía para promover la educación para el cultivo de lo humano, generando procesos de planificación y acción en la comunidad educativa con actividades político pedagógico que promuevan la autonomía del pensar en el marco de la educación para los valores humanos.

\section{Referencia bibliográfica}

Calandín J.G. (2018). El desafio ético de la educación. Editorial Dykinson S.L. Madrid, España.

Debord, G. (1997). La sociedad del espectáculo. Editorial BuchetChastel, París.

Foucault. M. (1976). Defender la sociedad. Fondo de Cultura Económica, Argentina.ondo de Cultura Económica, Argentina. 
Gramsci. A. (1967). La formación de los intelectuales. Editorial Grijalbo, S.A. México, Distrito Federal.

Geneyro. J.C. (1991). La democracia inquieta. Editorial Antropos. Universidad Autónoma Metropolitana. Centro de Estudios Constitucionales. 